\title{
PENGARUH LINGKUNGAN KELUARGA, LINGKUNGAN SEKOLAH DAN DISIPLIN DENGAN MOTIVASI SEBAGAI VARIABEL INTERVENING TERHADAP KETUNTASAN BELAJAR SISWA KELAS XI SMA ADABIYAH PADANG PADA MATA PELAJARAN MATEMATIKA
}

\section{THE EFFECT OF FAMILY ENVIRONMENT, SCHOOL ENVIRONMENT, AND DISCIPLINE WITH MOTIVATION AS INTERVENING VARIABLE TO MASTERY LEARNING STUDENTS IN XI CLASS SMA ADABIYAH PADANG ON MATHEMATICS SUBJECT}

\author{
Novi Yanti \\ Fakultas Ekonomi, Universitas Ekasakti \\ E-mail: dienqu955@gmail.com
}

\begin{abstract}
ABSTRAK
Penelitian ini bertujuan untuk mengetahui, (1) Pengaruh secara langsung dan tidak langsung lingkungan keluarga, lingkungan sekolah, dan disiplin terhadap ketuntasan belajar matematika siswa SMA Adabiyah Padang, (2) Sejauh mana kemampuan siswa SMA Adabiyah Padang dalam menuntaskan hasil belajar matematikanya. Populasi dalam penelitian ini adalah seluruh siswa kelas XI SMA Adabiyah Padang yang berjumlah 263 orang. Sampel diambil sebanyak 72 orang menggunakan rumus slovin. Penelitian ini merupakan penelitian kuantitatif. Variabel bebas yang dikaji dalam penelitian ini adalah Lingkungan keluarga (X1), Lingkungan Sekolah (X2), Disiplin (X3), Variabel terikatnya adalah Ketuntasan belajar (X5) dan variabel interveningnya adalah Motivasi Belajar (X4). Metode pengumpulan data yang digunakan adalah dokumentasi dan kuesioner (angket). Metode analisis data yaitu analisis deskriptif persentase dan analisis jalur (Path analysis). Persamaan Analisis Jalur yang diperoleh adalah sebagai berikut: SMA Adabiyah: $\mathrm{X} 4=0,236 \mathrm{X} 1+0,229 \mathrm{X} 2+0,269 \mathrm{X} 3+\mathrm{e}$, dan X5 =0,126 X1 + $0,298 \times 2+0,388 \times 4+$ e. Hasil analisis jalur menunjukkan bahwa, pengaruh langsung (LK-KB) sebesar 12,6\%, (DB-KB) sebesar 29,8\%, dan (MB-KB) sebesar 38,8\%. Dan pengaruh secara tidak langsung, (LK-MB-KB) sebesar 9,15\%, (LS-MB-KB) sebesar 8,90\%, (DS-MB-KS) sebesar 10,40\%. Berdasarkan hasil penelitian tersebut, sebaiknya SMA Adabiyah Padang harus terus memperhatikan lingkungan keluarga, lingkungan sekolah, disiplin, dan motivasi. Karena ke empat variabel tersebut mempunyai pengaruh yang signifikan terhadap ketuntasan belajar siswa baik secara langsung maupun tidak langsung.
\end{abstract}

Kata kunci: lingkungan keluarga, school, discipline, learning motivation, mastery learning student 


\begin{abstract}
This research aims to detemine: (1) The direct andin direct effect of on family environment, school environment, dicipline on students, and mastery learnin on mathematics subject through student motivation in SMA adabiyah Padang. (2) How far the student mastery learning on mathematics subject in SMA Adabiyah Padang. The population on this study is all of the students XI class in SMA Adabiyah as many as 263 students. The sample was selected using a Slovin Formula. Sample taken as many as 72 studensts. This research is a quantitative study. The independent variables were examined in this study is family environment (X1), school environment (X2), Discipline (X3), The dependent variable is the students matery learning (X5) and the intervening variable is learning motivation (X4). Data collected methods used are documentation and questionnaires. Methods of data analysis was descriptive analysis and path analysis. Equation path analysis on SMA Adabiyah is: X4 =0,236X1 +0,229 X2 +0,269 X3 +e, dan X5 $=0,126 X 1+0,298 X 2+0,388 X 4+e$. The result of path analysis showed that the direct effect $(L K-K B)$ by $12,6 \%,(D B-K B)$ by $29,8 \%$, and $(M B-K B)$ by 38,8\%. And indirect effect (LK-MB-KB) by 9,15\%, (LS-MB-KB) by 8,90\%, (DS-MB-KS) by 10,40\%. Based on these results, i recommend SMA Adabiyah Padang must continue to pay attention to the family environment, school environment, discipline and motivation. Due to the four variables has a significant impact on students' mastery learning, either directly or indirectly.
\end{abstract}

Keywords: family environment, school environment, discipline, learning motivation and mastery learning student

\title{
PENDAHULUAN
}

Pendidikan adalah hal yang sangat penting dan tidak dapat dipisahkan dalam kehidupan seseorang. Dengan pendidikan, kita dapat meningkatkan kualitas kehidupan seseorang. Oleh karena itu pemerintah selalu berupaya mendorong masyarakat untuk terus meningkatkan kualitas dirinya melalui pendidikan. Seperti yang tertuang dalam Undang-undang No. 20 Tahun 2003 tentang tujuan Pendidikan Nasional Bab II Pasal 3 yang berbunyi:

"Pendidikan Nasional bertujuan mengembangkan kemampuan dan membentuk watak serta peradaban bangsa yang bermartabat dalam rangka mencerdaskan bangsa, bertujuan untuk berkembangnya potensi peserta didik agar menjadi manusia yang beriman dan bertakwa kepada Tuhan YME, berakhlak mulia, sehat, berilmu, cakap, kreatif, mandiri dan menjadi warga negara yang demokratis serta bertanggung jawab".

Kualitas pendidikan dipengaruhi oleh tiga komponen, yaitu masukan, proses dan keluaran. Komponen-komponen tersebut saling berhubungan, terkait dan saling mendukung untuk mencapai tujuan pendidikan. Ketuntasan belajar peserta didik merupakan komponen keluaran yang diperoleh dari hasil suatu proses pembelajaran. Ketuntasan belajar yang harus dicapai peserta didik permata pelajaran dalam Kurikulum Berbasis Kompetensi (KBK), dikenal dengan sebutan Standar Ketuntasan Belajar Minimal (SKBM). Ketuntasan belajar tersebut dapat dilihat dengan menggunakan parameter prestasi belajar siswa dengan melihat nilai kognitif, karena 
aspek ini dinilai guru untuk melihat penguasaan pengetahuan sebagai ukuran pencapaian hasil belajar siswa (Tu'u, 2004: 76).

Ketuntasan belajar peserta didik dipengaruhi oleh beberapa faktor. Faktor - faktor tersebut terdiri atas komponen - komponen masukan dalam pendidikan itu sendiri. Menurut Slameto (2003:54), secara garis besar faktor-faktor yang mempengaruhi belajar peserta didik dapat digolongkan menjadi 2, yaitu faktor intern dan faktor ekstern. Faktor intern adalah faktor yang ada dalam diri peserta didik, diantaranya motivasi dan disiplin, sedangkan faktor ekstern adalah faktor yang datang dari luar peserta didik, diantaranya adalah lingkungan keluarga, lingkungan sekolah dan lingkungan masyarakat. Masalah ketuntasan dalam belajar merupakan masalah yang sangat penting bagi para siswa dalam mencapai keberhasilan belajarnya, terlebih bagi para siswa yang mengalami kesulitan belajar terutama untuk mata pelajaran Matematika.

Matematika merupakan bagian dari ilmu pengetahuan yang signifikan terhadap perkembangan ilmu pengetahuan dan sekaligus pembangunan sumber daya manusia. Matematika adalah induk dari ilmu pengetahuan yang sangat dibutuhkan manusia baik dalam diri pribadi maupun dalam masyarakat. Matematika melatih daya pikir logis sistematis dan melatih pemikiran dalam mencari jalan keluar terbaik dalam setiap masalah yang dihadapi.

Matematika memiliki peranan strategis untuk meningkatkan kualitas kehidupan manusia baik dalam pengembangan teknologi maupun dalam sosial budaya bermasyarakat. Erman Suherman dalam Mochtar Buchori (2003:60) menyatakan bahwa matematika merupakan salah satu pengetahuan umum minimum yang harus dikuasai warga negara agar dapat berkedudukan sejajar dengan warga negara lain. Pernyataan tersebut menandakan bahwa untuk dapat memiliki kehidupan yang layak, setiap warga negara wajib menguasai matematika.

Begitu pentingnya peranan matematika sehingga pada setiap jenjang pendidikan mulai dari pra sekolah, pendidikan dasar hingga pendidikan tinggi, matematika selalu diajarkan dengan menyesuaikan perkembangan aspek kognitif, afektif, dan psikomotorik siswa. Namun selama ini dalam proses pembelajaran dari jenjang sekolah dasar sampai perguruan tinggi, matematika masih dianggap sebagai pelajaran yang kurang menarik dan sulit untuk dipahami, sehingga banyak siswa yang merasa stress pada saat mengikuti pelajaran matematika yang pada akhirnya nilai ketuntasan tidak tercapai.

Berdasarkan survey pendahuluan yang telah dilakukan ternyata lebih dari $50 \%$ siswa yang menyatakan bahwa pelajaran Matematika adalah pelajaran yang paling menakutkan buat mereka. Kebanyakan siswa SMA Adabiyah Padang merasa kesulitan dalam memahami pelajaran matematika. SMA Adabiyah Padang masih menggunakan kurikulum KTSP (Kurikulum Tingkat Satuan Pendidikan) dan bukan menggunakan kurikulum 2013 dimana pembelajaran matematikanya dibagi menjadi dua yaitu matematika wajib dan matematika peminatan. Walaupun demikian, setiap guru disekolah ini masih berfokus pada ketuntasan belajar siswanya. 
Untuk mencapai ketuntasan belajar yang lebih baik diperlukan kerjasama dari berbagai pihak untuk membantu para siswa tersebut. Tidak hanya dibutuhkan motivasi dan disiplin yang tinggi namun dukungan keluarga dan para penyelenggara pendidikan juga sangat penting untuk mencapai keberhasilan siswa dalam menyelesaikan pembelajarannya.

Pembelajaran tuntas merupakan suatu pendekatan pembelajaran untuk memastikan bahwa semua siswa menguasai hasil pembelajaran yang diharapkan dalam suatu unit pembelajaran sebelum berpindah ke unit pembelajaran berikutnya. Pendekatan ini membutuhkan waktu yang cukup dan proses pembelajran yang berkualitas. Menurut Bloom (1968) pembelajaran tuntas merupakan satu pendekatan pembelajaran yang difokuskan pada penguasaan siswa dalam sesuatu hal yang dipelajari.

Berdasarkan hal tersebut maka dapat dirumuskan masalah sebagai berikut: 1) Seberapa besar pengaruh langsung dan tidak langsung Lingkungan keluarga, lingkungan sekolah, disiplin belajar dan motivasi belajar terhadap ketuntasan belajar Matematika siswa kelas XI SMA Adabiyah Padang. 2) Bagaimana kemampuan siswa SMA adabiyah Padang dalam menuntaskan hasil belajarnya. Adapun kerangka pemikiran penelitian ini seperti Gambar 1.

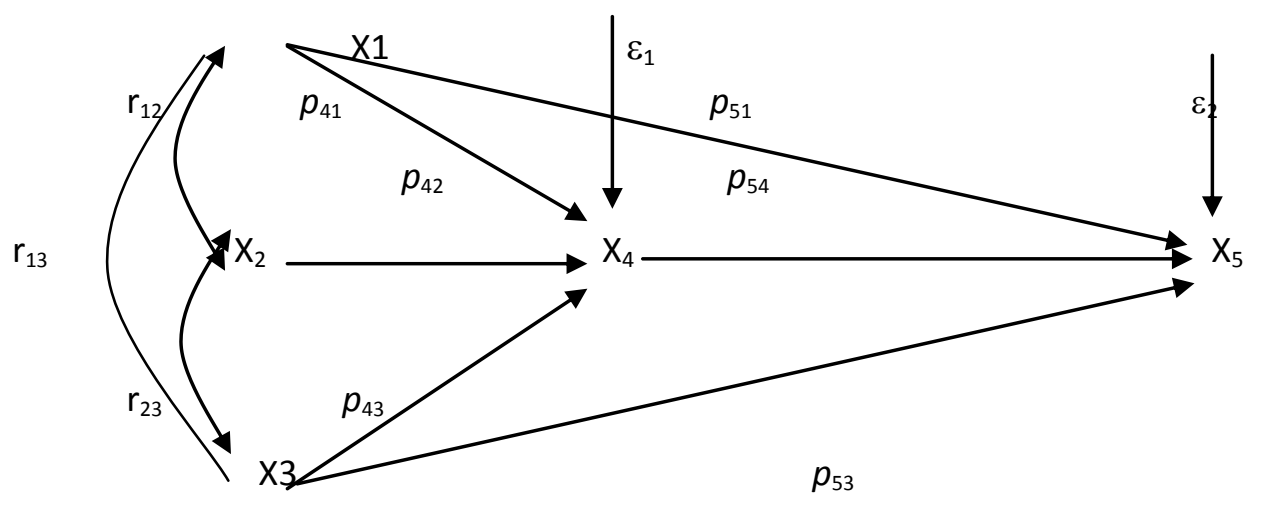

Gambar 1: Kerangka Konseptual Penelitian

Keterangan:

$\mathrm{X} 1 \quad$ = Lingkungan Keluarga

$\mathrm{X} 2 \quad$ = Lingkungan Sekolah

$\mathrm{X} 3=$ Disiplin

X4 = Motivasi

X5 = Ketuntasan Belajar

Berdasarkan kerangka konseptual diatas maka dapat dirumuskan hipotesis sebagai berikut: 
1. Diduga terdapat pengaruh yang signifikan Lingkungan keluarga terhadap motivasi belajar secara parsial

2. Diduga terdapat pengaruh yang signifikan lingkungan sekolah terhadap motivasi belajar secara parsial.

3. Diduga terdapat pengaruh yang signifikan disiplin belajar terhadap motivasi belajar secara parsial.

4. Diduga terdapat pengaruh yang signifikan motivasi belajar terhadap ketuntasan belajar.

5. Diduga terdapat pengaruh yang signifikan lingkungan keluarga terhadap ketuntasan belajar siswa.

6. Diduga terdapat pengaruh yang signifikan disiplin siswa terhadap ketuntasan belajar siswa.

7. Diduga terdapat pengaruh yang signifikan lingkungan keluarga, lingkungan sekolah, dan disiplin melalui motivasi belajar terhadap ketuntasan belajar

\section{METODE PENELITIAN}

Penelitian ini dilakukan di SMA Adabiyah Padang. Populasi penelitian ini adalah siswa kelas XI IPA dan IPS SMA Adabiyah yang berjumlah 263 orang. Sampel yang digunakan dalam penelitian ini diambil dengan menggunakan rumus slovin yaitu sebanyak 72 orang siswa.

Variabel bebas yang dikaji adalah lingkungan keluarga (X1), lingkungan sekolah (X2), disiplin belajar (X3). Variabel terikatnya adalah ketuntasan belajar (X5), dan variabel intervening adalah motivasi belajar (X4). Pengumpulan data dilakukan dengan cara dokumentasi dan angket. Metode analisis data menggunakan analisis deskriptif persentase dan analisis uji jalur. Analisis deskriptif persentase digunakan untuk mengetahui keadaan lingkungan keluarga, lingkungan sekolah, disiplin belajar, motivasi belajar dan ketuntasan belajar. Sedangkan analisis uji jalur digunakan untuk mengetahui pengaruh langsung maupun tidak langsung variabel bebas terhadap variabel terikat melalui variabel intervening.

\section{HASIL DAN PEMBAHASAN}

\section{Analisis Deskriptif Persentase}

Analisis deskriptif yang dipakai adalah deskriptif persentase. Dalam analisis ini semua skor dari masing-masing variabel maupun dari setiap sub variabelnya dijumlahkan dan dibandingkan dengan skor idealnya sehingga akan diperoleh persentase skor. Dari deskriptif persentase inilah selanjutnya dibandingkan dengan kriteria yang digunakan dan diketahui tingkatannya. Karena skor tertinggi dari masing-masing item adalah 5 dan skor terendahnya adalah 1 , maka dapat dihitung:

Persentase maksimal

$$
\begin{aligned}
& =\frac{5}{5} \times 60=60 \\
& =\frac{1}{5} \times 60=12
\end{aligned}
$$


Rentang

$$
\begin{array}{ll}
\text { Rentang } & =60-12=48 \\
\text { Panjang kelas interval } & =\frac{48}{5}=9,6 \text { digenapkan } 10
\end{array}
$$

Dengan panjang kelas interval 10 dan persentase minimal 12.

Berdasarkan hasil statistik deskriptif persentase variable-variabel penelitian lingkungan keluarga, lingkungan sekolah, disiplin belajar, motivasi belajar dan ketuntasan belajar. Hasil analisis diperoleh sebagai berikut:

Tabel 1. Hasil Perhitungan Deskriptif Persentase Lingkungan keluarga (X1) dan Lingkungan Sekolah (X2)

\begin{tabular}{cccrr}
\hline No & Kelas Interval Skor & Kriteria & \multicolumn{2}{c}{ Variabel } \\
\cline { 3 - 5 } & & & $\mathrm{X} 1$ & $\mathrm{X} 2$ \\
\hline 1 & $52<\%$ skor $<62$ & Sangat Baik & 8.34 & 9.72 \\
2 & $42<\%$ skor $<52$ & Baik & 72.22 & 62.50 \\
3 & $32<\%$ skor $<42$ & Sedang & 19.44 & 27.78 \\
4 & $22<\%$ skor $<32$ & Rendah & 0.0 & 0.0 \\
5 & $12<\%$ skor $<22$ & Sangat Rendah & 0.0 & 0.0 \\
\hline & Jumlah & 100 & 100 \\
\hline
\end{tabular}

Tabel 2. Hasil perhitungan Deskriptif Persentase Disiplin (X4) dan Motivasi (X5)

\begin{tabular}{cccrr}
\hline No & Kelas Interval Skor & Kriteria & \multicolumn{2}{c}{ Variabel } \\
\cline { 3 - 5 } & & & \multicolumn{1}{c}{ X3 } & \multicolumn{1}{c}{ X4.94 } \\
\hline 1 & $52<\%$ skor $<62$ & Sangat Tinggi & 58.61 \\
2 & $42<\%$ skor $<52$ & Tinggi & 52.78 & 43.06 \\
3 & $32<\%$ skor $<42$ & Sedang & 15.28 & 8.33 \\
4 & $22<\%$ skor $<32$ & Rendah & 0.0 & 0.0 \\
5 & $12<\%$ skor $<22$ & Sangat Rendah & 0.0 & 0.0 \\
\hline & Jumlah & 100 & 100 \\
\hline
\end{tabular}

Tabel 3. Hasil Perhitungan Deskriptif Persentase Ketuntasan Belajar Siswa

\begin{tabular}{cccc}
\hline No & Kelas Interval Skor & Kriteria & X5 \\
\cline { 3 - 4 } & & & SMA Adabiyah \\
\hline 1 & $90 \leq$ Nilai & Sangat Baik (A) & 12.50 \\
2 & $75<$ Nilai $<90$ & Baik (B) & 87.50 \\
3 & $60 \leq$ Nilai $\leq 75$ & Cukup (C) & 0.0 \\
4 & Nilai $<60$ & Kurang (D) & 0.0 \\
& Jumlah & & 100 \\
\hline
\end{tabular}

Sumber: Data primer diolah tahun 2015

Berdasarkan Tabel 1, 2, dan 3 dapat dilihat bahwa hasil deskriptif persentase lingkungan keluarga, lingkungan sekolah, disiplin dan motivasi siswa SMA rata-rata berada dalam kondisi baik atau tinggi. Begitu juga dengan ketuntasan belajar siswa SMA Adabiyah dimana sebagian besar ketuntasan belajar siswanya berada pada range 
70 sampai 90 dengan kriteria Baik sebanyak 87,50\%. Dan 12,50\% siswanya memiliki ketuntasan belajar sangat baik.

\section{Model Analisis Jalur SMA Adabiyah Padang}

Hasil penelitian mengenai pengaruh lingkungan keluarga (X1), lingkungan sekolah (X2), dan disiplin (X3) dengan motivasi (X4) sebagai variable intervening terhadap ketuntasan belajar siswa SMA Adabiyah kelas XI pada mata pelajaran matematika seperti yang terlihat pada Tabel 4 dan Tabel 5.

Tabel 4. Hasil Analisis Lingkungan Keluarga, Lingkungan Sekolah Dan Disiplin Terhadap Motivasi Belajar Siswa SMA Adabiyah Padang

Coefficients $^{\mathrm{a}}$

\begin{tabular}{|c|c|c|c|c|c|c|c|}
\hline \multirow[b]{2}{*}{ Model } & \multicolumn{2}{|c|}{$\begin{array}{l}\text { Unstandardized } \\
\text { Coefficients }\end{array}$} & \multirow{2}{*}{$\begin{array}{c}\text { Standardized } \\
\text { Coefficients } \\
\text { Beta }\end{array}$} & \multirow[b]{2}{*}{$\mathrm{T}$} & \multirow[b]{2}{*}{ Sig. } & \multicolumn{2}{|c|}{ Collinearity Statistics } \\
\hline & $\mathrm{B}$ & Std. Error & & & & Tolerance & VIF \\
\hline tant) & 14,019 & 6,542 & & 2,143 & ,036 & & \\
\hline & 278 & ,135 & 236 & 2,051 & ,044 & ,759 & 1,317 \\
\hline & ,263 & 130 & ,229 & 2,019 & ,047 & ,777 & 1,287 \\
\hline & ,243 & ,101 & ,269 & 2,408 & 019 & ,805 & 1,243 \\
\hline
\end{tabular}

sendent Variable: $\mathrm{X} 4$

Tabel 5. Hasil Analisis Lingkungan Keluarga, Disiplin Dan Motivasi Terhadap Ketuntasan Belajar Siswa SMA Adabiyah Padang

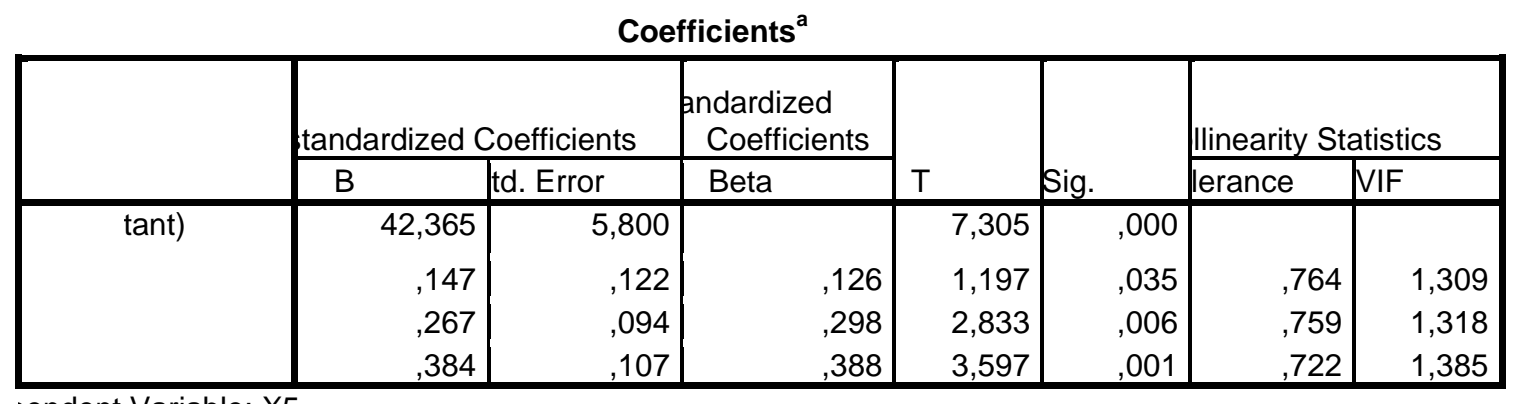

sendent Variable: X5

Berdasarkan tabel 4 dan 5, terlihat variabel lingkungan keluarga (X1), Lingkungan Sekolah (X2), disiplin (X3), dan motivasi (X4) memiliki nilai signifikansi $\rho$ value < a ( $0.000<0.05)$, sehingga koefisien jalurnya signifikan. Karena koefisien jalurnya signifikan maka dapat dibuat diagram jalurnya seperti Gambar 2. 


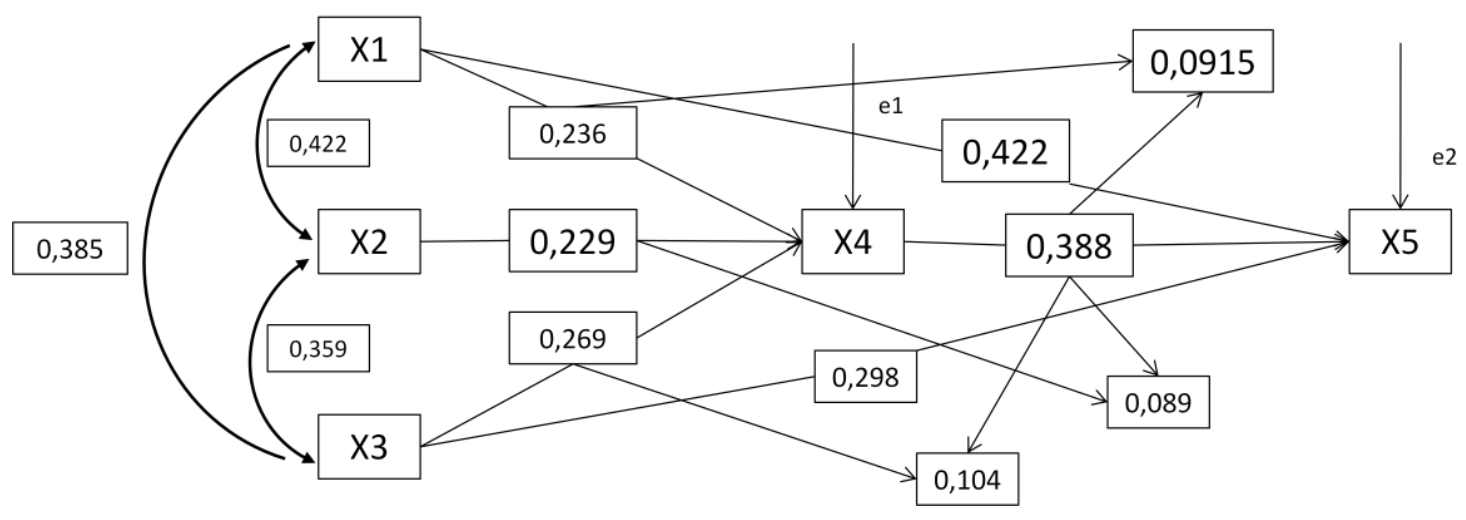

Gambar 2. Model Struktur Analisa Jalur Sumber: Tabel 4 dan Tabel 5 hasil pengolahan SPSS 19

Dari Gambar 2 di atas dapat dibuat persamaan struktur path analisisnya sebagai berikut:

\section{Persamaan Sub Struktur I}

$\mathrm{X} 4=0,236 \mathrm{X} 1+0,229 \mathrm{X} 2+0,269 \mathrm{X} 3+\mathrm{e}_{1}$

di mana: $e_{1}=\sqrt{ } 1-R^{2}=\sqrt{ } 1-0,319=0.565$

Artinya apabila terjadi kenaikan satu satuan lingkungan keluarga diikuti kenaikan motivasi belajar sebesar 0,236 satuan dan setiap kali terjadi kenaikan satu satuan lingkungan sekolah diikuti kenaikan motivasi belajar sebesar 0,229 serta apabila terjadi kenaikan satu satuan disiplin belajar akan diikuti kenaikan motivasi belajar sebesar 0,269 satuan.

\section{Persamaan Sub Struktur II}

$\mathrm{X} 5=0,126 \mathrm{X} 1+0,298 \mathrm{X} 3+0,388 \times 4+\mathrm{e}_{2}$

di mana $e_{2}=\sqrt{ } 1-R^{2}=\sqrt{ } 1-0,429=0,756$

Artinya apabila terjadi kenaikan satu satuan lingkungan keluarga diikuti kenaikan ketuntasan belajar siswa sebesar 0,126 satuan dan setiap kali terjadi kenaikan satu satuan disiplin siswa akan diikuti kenaikan ketuntasan belajar sebesar 0,298 satuan. Apabila terjadi kenaikan satu satuan motivasi belajar akan diikuti kenaikan ketuntasan belajar sebesar 0,388 satuan.

\section{Pengujian Hipotesis}

Hasil pengujian statistik dengan SPSS 19 pada tabel 4 dan 5 dapat di interpretasikan sebagai berikut:

1. Variabel lingkungan keluarga (X1) diperoleh nilai signifikansi 0,044<0,05, koefisien jalur ini signifikan. Hasil ini menunjukkan H1 diterima, yang berarti lingkungan keluarga berpengaruh signifikan terhadap motivasi belajar secara parsial. 
2. Varibel lingkungan sekolah (X2) diperoleh nilai signifikansi 0,047 <0,05, koefisien jalur ini signifikan. Hasil ini menunjukkan $\mathrm{H} 2$ diterima, artinya lingkungan sekolah berpengaruh signifikan terhadap motivasi belajar secara parsial.

3. Variabel disiplin (X3) diperoleh nilai signifikansi 0,019<0,05, koefisien jalur ini signifikan. Hasil ini menunjukkan H3 diterima, artinya disiplin berpengaruh signifikan terhadap motivasi belajar secara parsial.

4. Variabel Motivasi siswa (X4) diperoleh nilai signifikansi 0,001 < 0,05, koefisien jalur ini signifikan. Hasil ini menunjukkan H4 diterima, artinya Motivasi siswa berpengaruh signifkan terhadap ketuntasan belajar secara parsial.

5. Variabel lingkungan keluarga (X1) diperoleh nilai signifikansi 0,035<0,05, koefisien jalur ini signifikan. Artinya lingkungan keluarga berpengaruh signifikan terhadap ketuntasan belajar siswa atau $\mathrm{H} 5$ diterima.

6. Variabel Disiplin siswa (X3) diperoleh nilai signifikansi 0,006 $<0,05$, koefisien jalur ini signifikan. Hasil ini menunjukkan H6 diterima, artinya disiplin berpengaruh signifikan terhadap ketuntasan belajar siswa.

Berdasarkan Gambar 2, dapat diinterpretasikan bahwa pengaruh langsung (LK-KB) sebesar 12,6\%; (DB-KB) sebesar 29,8\%; (MB-KB) sebesar 38,8\%. Pengaruh tidak langsung (LK-MB-KB) sebesar 9,15\%; (LS-MB-KB) sebesar 8,90\% dan (DS-MB-KB) sebesar $10,40 \%$.

\section{SIMPULAN}

Berdasarkan hasil penelitian dan pembahasan dapat diambil kesimpulan sebagai berikut:

a. Keempat variabel eksogen yaitu lingkungan keluarga (X1), lingkungan sekolah (X2), disiplin (X3) dan motivasi (X4) mempunyai pengaruh langsung dan tidak langsung terhadap ketuntasan belajar siswa (X5) dimana koefisien jalurnya untuk masingmasing variabel ini adalah signifikan dimana $\rho$ value $<a(0,05)$. Hal ini berarti Ho ditolak dan Ha diterima.

b. Ketuntasan belajar siswa SMA Adabiyah Padang sebagian besar berada pada kategori baik dan hanya sebagian kecil saja siswanya yang memiliki ketuntasan belajar sangat baik.

c. Dari hasil deskriptif persentase, kondisi lingkungan keluarga, lingkungan sekolah dan disiplin siswa SMA Adabiyah Padang rata-rata berada dalam kategori baik. Sedangkan untuk variabel motivasi dimana sebagian besar siswa SMA Adabiyah Padang sudah mempunyai motivasi yang lebih tinggi.

\section{SARAN}

Berdasarkan kesimpulan tersebut diatas peneliti menyarankan hal-hal sebagai berikut:

a. Bagi SMA Adabiyah Padang dan orang tua siswa agar selalu memperhatikan kondisi lingkungan keluarga, lingkungan sekolah, disiplin dan motivasi siswanya agar dalam pelaksanaan pembelajaran dapat berjalan efektif dan lancar sesuai tujuan yang diharapkan. Selain itu guru harus bisa menciptakan metode pembelajaran matematika yang menyenangkan dan tidak membosankan serta memberikan 
reward kepada siswa ketika mereka mendapatkan nilai yang tinggi. Hal ini tentunya bertujuan untuk meningkatkan motivasi diantara sesama siswa sehingga mereka berlomba-lomba untuk meraih prestasi (ketuntasan belajar) yang lebih baik.

b. Orang tua dan guru harus bekerjasama untuk selalu memantau dan memperhatikan disiplin anak-anak mereka. Disiplin akan tercapai jika seseorang menyadari akan pentingnya disiplin bagi dirinya baik di sekolah maupun di rumah. Peranan orang tua dan guru ini sangat penting untuk penegakkan kedisiplinan anak dalam pembelajaran, baik di rumah maupun disekolah. Hal ini dikarenakan jika seorang anak mempunyai disiplin yang tinggi maka dia akan meraih kesuksesan dalam hidupnya dimanapun ia berada.

\section{UCAPAN TERIMA KASIH}

Penulis mengucapkan terima kasih kepada Kepala Sekolah SMA Adabiyah Padang dan jajarannya yang telah membantu memberikan data dan informasi terkait penelitian ini. Terima kasih juga kepada LPPM UNES yang telah memfasilitasi pelaksanaan penelitian dan publikasi artikel ini.

\section{DAFTAR PUSTAKA}

Arikunto, Suharsimi. 2002. Prosedur Penelitian Suatu Pendekatan Praktek. Jakarta: PT. Rineka Cipta.

Bloom, B.S. 1976. Human Characteristics and Social Learning New York. McGraw-Hill.

Brown, B.W and Daniel H. 1980. Saks Production Technologies and Resource Allocation Within Classroom and Schools: Theory and Measurement dalam The Analysis of Edcational Productivity, Vol I: Issues In Microanalysis, Diedit oleh Robert Dreeben and J. Alan Thomas; Cambridge, Mass: Bafiinger Publishing Company.

Novi, Yanti. 2013. Tesis: Pengaruh Motivasi dan Disiplin terhadap Prestasi Belajar Siswa SMP Islam Terpadu Gema Nurani.

Slameto. 2003. Belajar dan Faktor-faktor Yang Mempengaruhinya. Jakarta:Rineka Cipta

Tu'u, Tulus. 2004. Peran Disiplin Pada Perilaku dan Prestasi Siswa. Jakarta:Grasindo 